\title{
Dynamical and thermodynamical coupling between the North Atlantic subtropical high and the marine boundary layer clouds in boreal summer
}

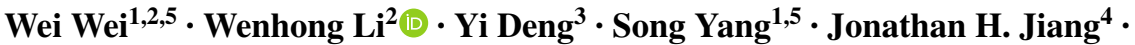 \\ Lei Huang ${ }^{4}$ W. Timothy Liu ${ }^{4}$
}

Received: 20 December 2016 / Accepted: 4 June 2017

(c) Springer-Verlag GmbH Germany 2017

\begin{abstract}
This study investigates dynamical and thermodynamical coupling between the North Atlantic subtropical high (NASH), marine boundary layer (MBL) clouds, and the local sea surface temperatures (SSTs) over the North Atlantic in boreal summer for 1984-2009 using NCEP/ DOE Reanalysis 2 dataset, various cloud data, and the Hadley Centre sea surface temperature. On interannual timescales, the summer mean subtropical MBL clouds to the southeast of the NASH is actively coupled with the NASH and local SSTs: a stronger (weaker) NASH is often accompanied with an increase (a decrease) of MBL clouds and abnormally cooler (warmer) SSTs along the southeast flank of the NASH. To understand the physical processes between the NASH and the MBL clouds, the authors conduct a data diagnostic analysis and implement a numerical modeling investigation using an idealized anomalous atmospheric general circulation model (AGCM). Results suggest that significant northeasterly anomalies in the southeast flank of the NASH associated with an intensified NASH tend to induce stronger cold advection and coastal
\end{abstract}

Wenhong Li

Wenhong.li@duke.edu

1 School of Atmospheric Sciences, Sun Yat-sen University, Guangzhou, China

2 Earth and Ocean Sciences, Nicholas School of the Environment, Duke University, Durham, NC 27708-0328, USA

3 School of Earth and Atmospheric Sciences, Georgia Institute of Technology, Atlanta, GA, USA

4 Jet Propulsion Laboratory, California Institute of Technology, Pasadena, CA, USA

5 Guangdong Province Key Laboratory for Climate Change and Natural Disaster Studies, Sun Yat-sen University, Guangzhou, China upwelling in the MBL cloud region, reducing the boundary surface temperature. Meanwhile, warm advection associated with the easterly anomalies from the African continent leads to warming over the MBL cloud region at $700 \mathrm{hPa}$. Such warming and the surface cooling increase the atmospheric static stability, favoring growth of the MBL clouds. The anomalous diabatic cooling associated with the growth of the MBL clouds dynamically excites an anomalous anticyclone to its north and contributes to strengthening of the NASH circulation in its southeast flank. The dynamical and thermodynamical couplings and their associated variations in the NASH, MBL clouds, and SSTs constitute an important aspect of the summer climate variability over the North Atlantic.

Keywords North Atlantic subtropical high - Marine boundary layer clouds $\cdot$ Sea surface temperatures . Dynamical and thermodynamical coupling processes

\section{Introduction}

The low-level subtropical anticyclone over the North Atlantic is a fundamental element of the atmospheric circulation (Fig. 1). The anticyclone, also known as the North Atlantic subtropical high (NASH), connects the tropical trade wind regime with the midlatitude westerly belt in the low troposphere (Davis et al. 1997; Seager et al. 2003). During summer, the subtropical high system plays an important role in altering moisture transport ( $\mathrm{Li}$ et al. 2013a), and thus modulating regional precipitation and hydrological extremes in the Midwest (Cook et al. 2008) and southeastern United States (Stahle and Cleaveland 1992; Li et al. 2011, 2012a, 2013a). Providing critical large-scale steering flow for the North Atlantic hurricanes and tropical storms, the NASH 
Fig. 1 Summertime climatology of a stream function at $925 \mathrm{hPa}$ (unit: $10^{6} \mathrm{~m}^{2} \mathrm{~s}^{-1}$ ) and b sea level pressure (unit: $\mathrm{hPa}$ ) during 1984-2009 based on NCEP/DOE Reanalysis 2. The NPSH and NASH are dominant high-pressure systems over the North Pacific and the North Atlantic, respectively (a) SF 925

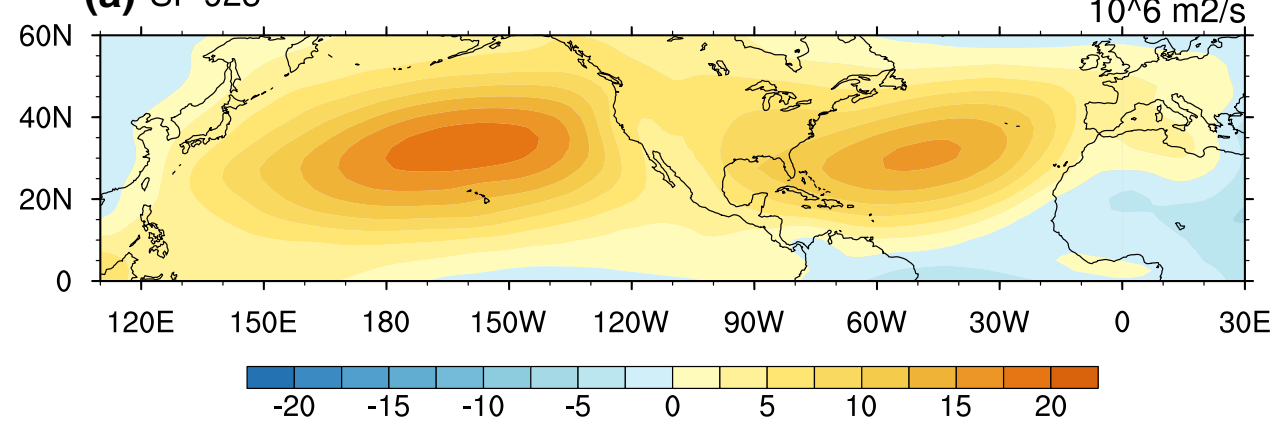

(b) SLP

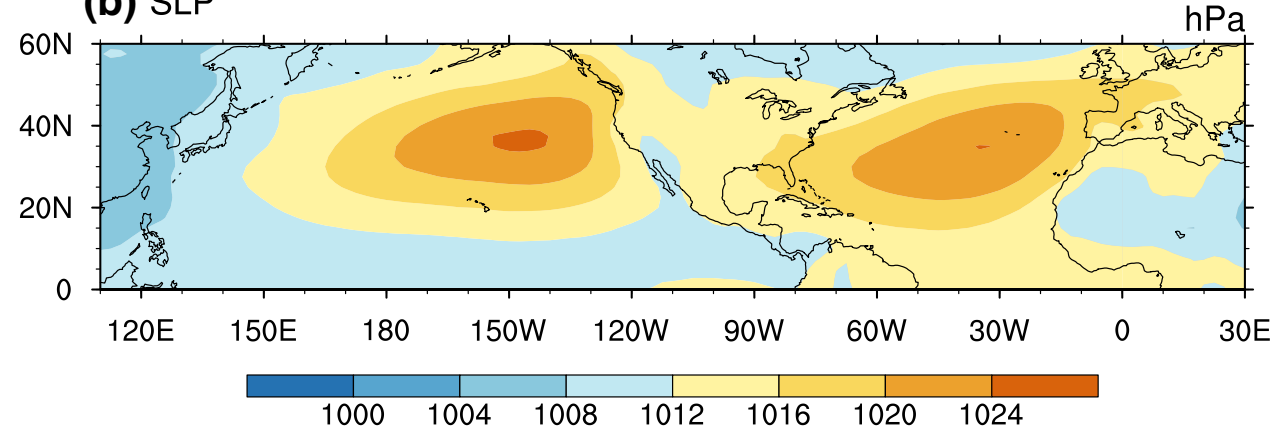

circulation and its intensity also largely determine the movement of tropical cyclones (Elsner and Tsonis 1993; Colbert and Soden 2012).

Marine boundary layer (MBL) clouds play a vital role in the Earth's climate system (Klein and Hartmann 1993; Miller 1997; Norris et al. 1998; Bony and Dufresne 2005; Clement et al. 2009; Wood 2012; Huang et al. 2015; Zhai et al. 2015). Previous studies have suggested that MBL clouds and associated radiative energy are central to many questions regarding climate change, and have been identified as a primary source of uncertainty in determining the sensitivities of climate models (Bony and Dufresne 2005; Randall et al. 2007; Zhai et al. 2015). The uncertainty is, to the first order, due to the lack of knowledge of the physical processes that contribute to the cloud-climate feedback (Yue et al. 2011). MBL clouds occur most frequently in the large-scale subsidence regions over eastern subtropical oceans, co-located with the subtropical highs (Norris 1998). The MBL cloud macro and micro properties and their diurnal/seasonal cycles have been studied using 19 months in situ measurements and remote sensing data (Dong et al. 2014a, b, 2015). The interactions between the clouds, large-scale atmospheric circulation, and the underlying oceans are important to understand the Earth's climate and its changes.

Previous observational and modeling studies have suggested a positive feedback between the MBL clouds, sea surface temperatures (SSTs), and subtropical highs over the eastern Pacific (Norris and Leovy 1994; Norris 1998; Clement et al. 2009; Nigam and Chan 2009; He 2009). In the subtropical North Pacific, MBL clouds are located off the California coast, inducing a strong longwave radiative cooling in the subtropical North Pacific (Norris 1998; Wu et al. 2009). The northerly flow along the eastern flank of the North Pacific Subtropical High (NPSH) generates cold air advection from high latitudes and coastal upwelling along the west coast of the continent. The latter lowers local SSTs and favors enhanced MBL cloudiness by modifying the structure of the planetary boundary layer (Klein and Hartmann 1993; Norris and Klein 2000; Clement et al. 2009). The strong longwave radiative cooling and enhanced subsidence induced by MBL clouds off the California coast in return tend to intensify the NPSH to its observed strength (Seager et al. 2003; Li et al. 2012b). In the subtropical North Pacific, northerly wind plays an important role in maintaining the feedback loop between the NPSH, observed MBL cloud amounts, and local SSTs (Norris et al. 1998; Seager et al. 2003; Clement et al. 2009; Wu et al. 2009).

Compared to the subtropical North Pacific, much less is known about the mechanisms for the coupling between the MBL clouds over the North Atlantic and the NASH at interannual timescales. The NASH is relatively weaker than the NPSH, based on both the circulation $(925 \mathrm{hPa}$ stream function) and mass (sea level pressure, SLP) data. The shape of the NASH is also different from that of the NPSH (see details in Sect. 3.1). In the subtropical North Atlantic, the MBL clouds are mainly located over the eastern subtropical Atlantic (Fig. 2) where the maximum cloud coverage is closer to the equator compared to that over the North 
Fig. 2 Summertime climatology of a low-level cloud amount from the International Satellite Cloud Climatology Project (ISCCP) from 1984 to 2009; b CERES low-level cloud (liquid and ice stratocumulus and stratus cloud fractions) from 2000 to 2016; and $\mathbf{c}$ total cloud amount from the International Comprehensive Ocean-Atmosphere Data Set (ICOADS) from 1979 to 2015 over the North Atlantic and the North Pacific. The color bar represents the cloud amount in percentage. Numbers indicate the average cloud amount in percentage in the red boxes. Climatological horizontal winds at $925 \mathrm{hPa}$ (vectors) from NCEP/DOE Reanalysis 2 are also plotted (unit: $\mathrm{m} \mathrm{s}^{-1}$ )

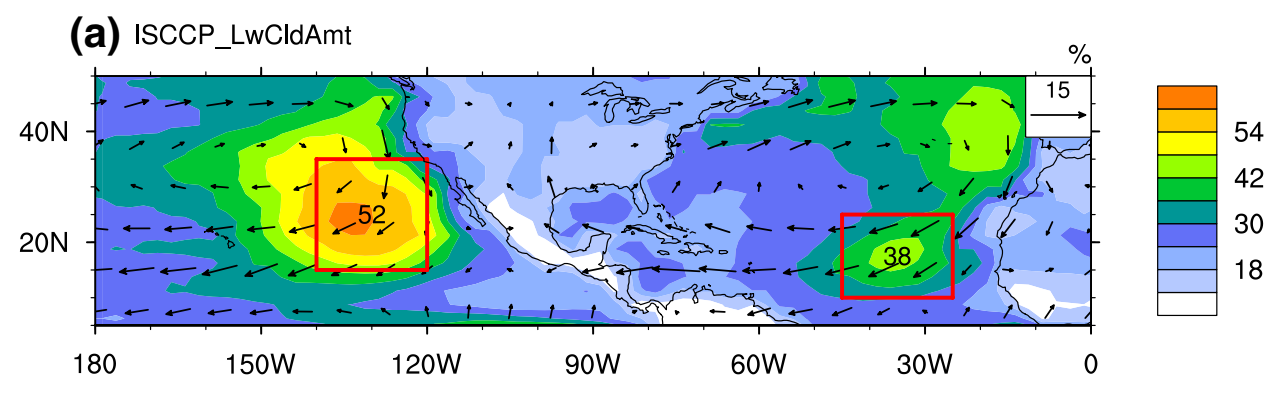

(b) CERES_LwCIdAmt

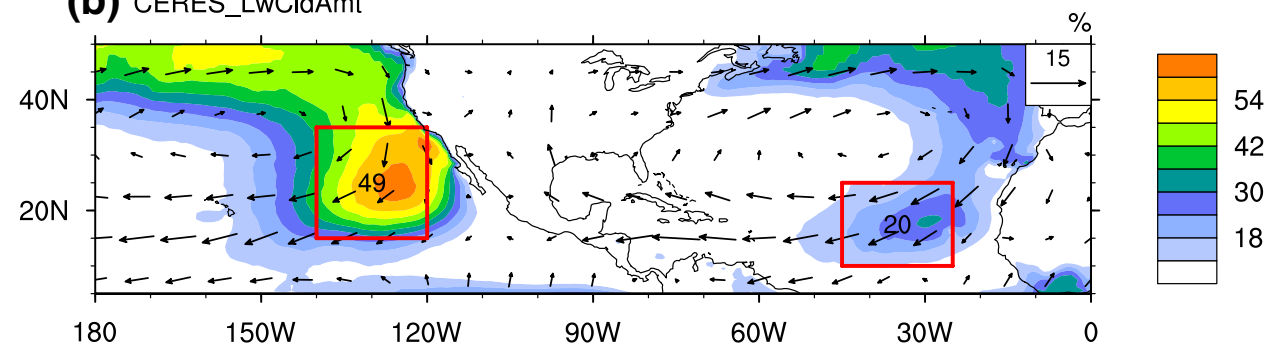

(c) ICOADS_CIdAmt

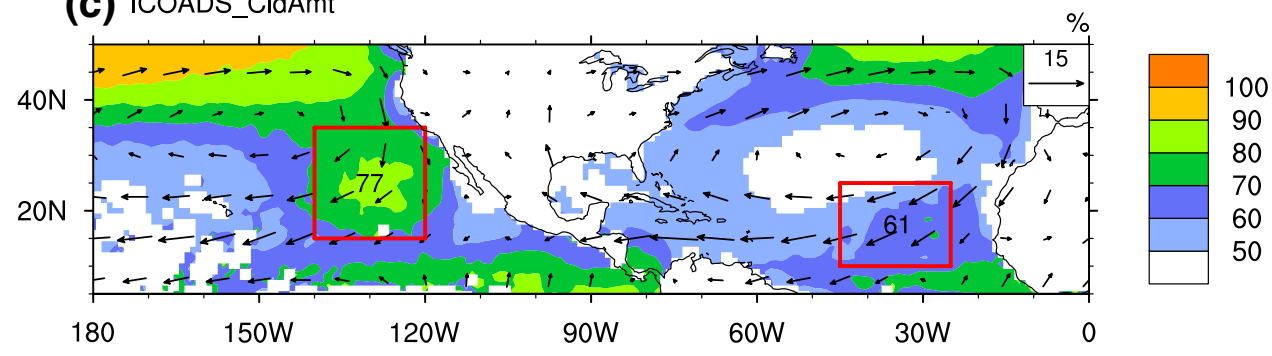

Pacific (Zhang et al. 2010). The amount of the MBL clouds in the subtropical North Atlantic is about $14 \%$ less than that in the North Pacific (Fig. 2a). These differences suggest the importance of the tropical easterly trade winds in the MBL clouds-subtropical high coupling process over the North Atlantic. The mechanism for a comprehensive dynamical and thermodynamical coupling between the MBL clouds, the NASH, and local SSTs has not been fully understood. Insufficient knowledge of the physical processes is suggested as the main reason for the biases in representing the NASH intensity, total amount of MBL clouds, and local energy budget in the state-of-the-art Global Climate Models (GCMs; Bony and Dufresne 2005; Randall et al. 2007; Li et al. 2012b).

This paper examines the dynamical and thermodynamical interactions between the summertime MBL clouds, NASH circulation, and local SSTs in the subtropical North Atlantic using various cloud data, SSTs, and atmospheric reanalysis data. In the following section, data and methods are described. Section 3 discusses the relationship between the MBL clouds and both the tropical easterly trade winds and northerly winds associated with the NASH respectively. The factors/processes that are keys to the dynamical and thermodynamical coupling between the MBL clouds, the NASH, and SSTs over tropical North Atlantic are also investigated in this section. Conclusions and discussions are given in Sect. 4.

\section{Data and methods}

\subsection{Data}

The monthly mean reanalysis data used in this study are extracted from the National Centers for Environmental Prediction (NCEP)/Department of Energy (DOE) Reanalysis 2 (NCEP-2) from 1984 to 2009 on a $2.5^{\circ} \times 2.5^{\circ}$ horizontal resolution (Kanamitsu et al. 2002). The global SSTs are derived from the Hadley Centre Sea Ice and Sea Surface Temperature data set (HadISST) (Rayner et al. 2003). 3D monthly ocean state variables from the Simple Ocean Data Assimilation ocean/sea ice reanalysis (SODA) version 3.3.1 (Carton and Giese 2008; Carton et al. 2016) are used to reveal ocean currents variation associated with the NASH (http://www.atmos.umd.edu/ ocean/index.htm).

Considering the possible problems of surface-based cloud observations and satellite-based cloud observations (Norris 1998; Clement et al. 2009), we examine independent cloud 
data sets with longer records. Monthly mean of low cloud amount is provided by the International Satellite Cloud Climatology Project (ISCCP) Stage D2 data from 1984 to 2009 (Rossow and Schiffer 1991). The ISCCP collects satellite data from the NOAA POES satellites as well as various meteorological geostationary satellites around the world in an effort to characterize global cloudiness. The low-level cloud fraction from Clouds and the Earth's Radiant Energy System (CERES) (Wielicki et al. 1996) and the total cloud amount from the International Comprehensive Ocean-Atmosphere Data Set (ICOADS) (Freeman et al. 2016) are analyzed to compare with the ISCCP D2 data on the spatial distribution of the MBL clouds and to adjust the interannual variation of the ISCCP D2 data. CERES ISCCP-D2like product provides CERES-MODIS and GEO cloud properties stratified by ISCCP cloud types and in the similar D2 format. We examined liquid and ice stratocumulus and stratus cloud fractions from CERES Merged Terra/Aqua/GEO ISCCP-D2like_ Ed3A data set from 2000 to 2016 on a $1^{\circ} \times 1^{\circ}$ horizontal resolution in this study. Cloud amounts in the ICOADS dataset are derived from NOAA/OAR/ESRL PSD, which are not categorized based on cloud types. However, over the east coast where the total clouds are dominated by MBL clouds (Schubert et al. 1979; Norris and Leovy 1994; Bellomo et al. 2016), the total cloud amount from ICOADS could be considered as the reference data (see Sect. 3.1.2 for detailed discussion). We changed the unit of ICOADS cloudiness data from okta to percent by dividing the data by 8 and then multiplying by 100 . The ISCCP low cloud amount data as well as the ICOADS total cloud data are de-trended to avoid spurious long-term change caused by satellite artifacts (Clement et al. 2009). The summer mean (June-July-August) records during 1984-2009 are analyzed in this study.

\subsection{Methods}

Previous studies have confirmed that the formation and variation of summertime subtropical highs are mainly determined by the spatial distribution and variations of diabatic heating (Rodwell and Hoskins 2001; Wu and Liu 2003; Liu et al. 2004; Miyasaka and Nakamura 2005; Wei et al. 2014, $2015,2017)$. We use the apparent heat source $Q_{1}$ to analyze the diabatic heating anomaly associated with the MBL clouds over the North Atlantic. $Q_{1}$ is calculated as a residual in the thermodynamic equation as following Yanai et al. (1973) and Luo and Yanai (1984):

$Q_{1}=C_{p}\left[\frac{\partial T}{\partial t}+\vec{V} \cdot \nabla T+\left(\frac{p}{p_{0}}\right)^{\kappa} \omega \frac{\partial \theta}{\partial p}\right]$

where $T$ is temperature; $\theta$ is potential temperature; $V$ is horizontal wind; and $\omega$ is vertical $p$ velocity. $\kappa=R / C_{p} ; R$ and $C_{p}$ are the gas constant and the specific heat at constant pressures of dry air; and $p_{0}=1000 \mathrm{hPa}$.

\subsection{Model}

To further investigate the feedback effect of the subtropical North Atlantic MBL clouds on the NASH, an anomalous atmospheric general circulation model (AGCM) is employed in this study. The model is a dry version of the Princeton AGCM (Held and Suarez 1994) linearized by specifying the 3-dimensional summer mean (JJA) basic state, so that model response to specific anomalous heating such as radiative cooling associated with the MBL clouds under the realistic basic mean state could be examined (Jiang and Li 2005; Li 2006). This anomalous AGCM is run with a T42 horizontal resolution, and uses a sigma $\left(\sigma=p / p_{s}\right)$ vertical coordinate with five evenly distributed levels from the top level at $\sigma=0$ to the bottom level at $\sigma=1$ with an interval of 0.2 . The subtropical circulation response to the heating will be examined, and the Newtonian cooling rate of $1 \mathrm{~K} \mathrm{day}^{-1}$ is applied for the region beyond $50^{\circ} \mathrm{N}$ and $50^{\circ} \mathrm{S}$. The model has been successfully applied to study the effect of latent heat release in the Indian and East Asian monsoon regions on the South Asian high (Wei et al. 2014, 2015) and to examine the atmospheric response to the heating over the Kuroshio Extension region (Wang et al. 2012).

\section{Results}

\subsection{Climatological feature and relationship between the NASH and MBL clouds}

\subsubsection{The NASH}

Figure 1 shows the climatology of summertime low-level circulation (stream function) and mass (SLP) fields in the Northern Hemisphere. Clearly, the NPSH and the NASH are two dominant low-level anticyclonic, high-pressure systems over the North Pacific and the North Atlantic, respectively. These systems are much stronger in summer than in winter, indicating the importance of zonally asymmetric diabatic heatings (Rodwell and Hoskins 2001; Miyasaka and Nakamura 2005; Wu and Liu 2003). Differences exist between the two summertime subtropical anticyclones. First, the intensity of NASH is relatively weaker than NPSH in summer. Specifically, the circulation field presented by $925 \mathrm{hPa}$ stream function shows that the NASH center is about $15.6 \times 10^{6} \mathrm{~m}^{2} \mathrm{~s}^{-1}, 3.5 \times 10^{6} \mathrm{~m}^{2} \mathrm{~s}^{-1}$ weaker than that of the NPSH (Fig. 1a). Using mass field represented by SLP, the NASH central pressure is $1024 \mathrm{hPa}$, slightly lower $(0.5 \mathrm{hPa})$ than that of the NPSH (Fig. 1b). Secondly, the shapes of the NASH and the NPSH are 
different (Fig. 1b). The oval-shaped NPSH bestrides over the North Pacific from east to west with its ridge line ${ }^{1}$ in an east-west orientation at about $35^{\circ} \mathrm{N}$ (Fig. 2). However, the NASH spans the North Atlantic with a ridge line in a northeast-southwest orientation. The climatological western ridge of the NASH (over $90^{\circ}-60^{\circ} \mathrm{W}$ ) is at about $29^{\circ} \mathrm{N}$, while the eastern ridge (over $30^{\circ}-10^{\circ} \mathrm{W}$ ) is at about $37.5^{\circ} \mathrm{N}$, due presumably to the different distribution of land-sea thermal contrast (Rodwell and Hoskins 2001; Miyasaka and Nakamura 2005) associated with different topographies of the North American and African continents. Compared to the northwest-southeast orientated coastline along the western North America which favors northerly wind along the east flank of the NPSH (Norris et al. 1998; Seager et al. 2003), the coastline along the western African continent is northeast-southwest orientated. Northeasterly/easterly winds, instead of the northerly winds, dominate the east flank of the NASH (Fig. 2) and likely play a more important role in maintaining and modulating the subtropical anticyclone-MBL cloud feedback loop in boreal summer.

\subsubsection{MBL clouds}

The summertime climatology of low-level clouds over Northern Hemisphere subtropical oceans is shown in Fig. 2a. The ISCCP data indicate that the MBL clouds are mainly located over the eastern oceans. Specifically, over the North Pacific, MBL clouds are concentrated over the area of $15^{\circ}-35^{\circ} \mathrm{N}, 145^{\circ}-120^{\circ} \mathrm{W}$. The maximum cloud coverage is located at about $25^{\circ} \mathrm{N}$ with cloud amount over $60 \%$. Observational studies reveal that MBL clouds are coupled well with the northerly winds along the east flank of the NPSH (Norris 2000; Clement et al. 2009). However, over the North Atlantic, high-amounts MBL clouds occur over the regions $10^{\circ}-25^{\circ} \mathrm{N}, 45^{\circ}-25^{\circ} \mathrm{W}$ and $32.5^{\circ}-50^{\circ} \mathrm{N}$, $30^{\circ}-10^{\circ} \mathrm{W}$, respectively; and a zone of relatively low MBL cloud amount could be found over the eastern North Atlantic between $25^{\circ}-30^{\circ} \mathrm{N}$. The southern MBL clouds with cloud amount of about $38 \%$, are located more equatorward with a center at about $17.5^{\circ} \mathrm{N}$ in comparison to the clouds over the North Pacific. The northern MBL clouds located at the higher latitudes are likely tied to the North Atlantic storm track (Zhang et al. 2004), and they do not stand out as clearly as the southern cloud center based on the CloudSat 2B-CLDCLASS data (Sassen and Wang 2008) and the Cloud-Aerosol Lidar and Infrared Pathfinder Satellite Observations (CALIPSO) GCM Oriented Cloud Calipso

\footnotetext{
1 The ridge-line of the subtropical highs is where winds with an easterly component reverse to winds with a westerly component, or mathematically it fulfills that $u=0$ and $\frac{\partial u}{\partial y}>0$, where $u$ is the zonal wind component (Liu and Wu 2004).
}

Product (CALIPSO-GOCCP) (Chepfer et al. 2010; also see below for detail). The spatial pattern of the low-level cloud from CERES data is similar to that of ISCCP data, i.e., high-amounts MBL clouds occur over eastern North Pacific $\left(15^{\circ}-35^{\circ} \mathrm{N}, 140^{\circ}-120^{\circ} \mathrm{W}\right)$ and the eastern North Atlantic region $\left(10^{\circ}-25^{\circ} \mathrm{N}, 45^{\circ}-25^{\circ} \mathrm{W}\right)$ although the cloud amount over the eastern North Atlantic is about 18\% lower than that in the ISCCP data (Fig. 2b). Previous studies found that the cloud amounts from both CRERS TRMM and Terra were in excellent agreement with the zonal means from long-term surface observations and were generally 0.07-0.08 less than those from ISCCP D2 dataset (Rossow and Schiffer 1999; Minnis et al. 2004), similar to our results. The differences in the amount and distribution of the MBL clouds over the subtropical North Atlantic compared to those over the North Pacific further suggest that the coupling processes between the NASH, MBL clouds, and local SSTs could be different and need to be studied.

Analysis from the ICOADS data demonstrates similar results as the ISCCP data, although only total cloud amount is provided in the ICOADS. Over eastern subtropical oceans, clouds are mainly MBL clouds (Schubert et al. 1979; Norris and Leovy 1994; Bellomo et al. 2016), and thus the total cloud data from the ICOADS largely indicate the amounts and patterns of the MBL clouds over the eastern Northern Hemisphere subtropical oceans (Fig. 2b, also see discussion below). The total cloud amount concentrated over the eastern subtropical North Pacific is $77 \%$, comparable with the MBL clouds using the ISCCP data. The cloud over the North Atlantic is also concentrated at lower latitudes with $61 \%$ cloud amount, similar to the ISCCP cloud data. Moreover, a low cloud amount zone could be found over the Canarian region at about $25^{\circ}-30^{\circ} \mathrm{N}$. These similarities of cloud pattern and cloud amount revealed by the ISCCP low cloud data (Fig. 2a), CERES low cloud amount (Fig. 2b) and the ICOADS total cloud data (Fig. 2c) demonstrate that total clouds are dominated by low-level clouds over the eastern North Atlantic and the eastern North Pacific, similar to the conclusions drawn by Bellomo et al. (2016). The low-level cloud distributions based on the CloudSat 2B-CLDCLASS data (Sassen and Wang 2008) and the CALIPSO-GOCCP data (Chepfer et al. 2010) confirm that MBL clouds are formed at more equatorward locations over the North Atlantic compared to those over the North Pacific, i.e., maximum low-level cloud amount is observed at about $15^{\circ}-25^{\circ} \mathrm{N}, 40^{\circ}-20^{\circ} \mathrm{W}$ over the eastern North Atlantic (not shown because the CALIPSO-GOCCP and CloudSat 2B-CLDCLASS data are 3 dimensional, not exactly the same as the 2-D data of the ISCCP and ICOADS). We thus focus on the southern MBL cloud over the North Atlantic in this study.

We also analyze the interannual variations of the lowlevel cloud amount in the ISCCP and the total cloud 


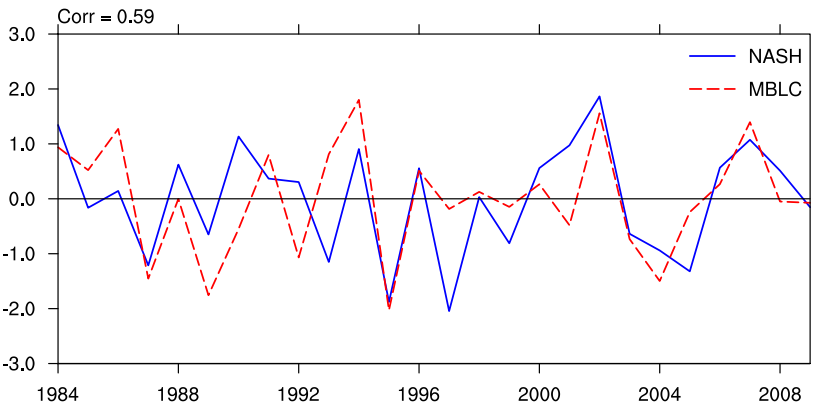

Fig. 3 Standardized detrended time series of the NASH index (blue solid line) based on NCEP/DOE Reanalysis 2 and the North Atlantic MBL cloud index based on the ISCCP low cloud amount (red dashed line) from 1984 to 2009

amount in ICOADS. Results show that the interannual variations of cloud amount in these two datasets are highly correlated after detrending, exceeding the 0.01 significance level (not shown). This feature suggests that the detrended ISCCP D2 data could reasonably depict the interannual variation of the MBL clouds over the eastern North Atlantic and the eastern North Pacific.

In summary, both surface-based (i.e. ICOADS) and satellite-based (i.e. ISCCP and CERES) cloud observations show that the maximum cloud coverage over the subtropical North Atlantic is located at the southeast flank of the NASH $\left(10^{\circ}-25^{\circ} \mathrm{N}, 45^{\circ}-25^{\circ} \mathrm{W}\right)$; the MBL cloud is about $14 \%$ (ISCCP) less in cloud amount and $8^{\circ}$ closer to the equator in the subtropical North Atlantic compared to that in the North Pacific.

\subsubsection{Relationship between the NASH and MBL clouds}

To understand the possible relationship between the NASH and MBL clouds over the subtropical North Atlantic, we first define a NASH intensity index as the standardized detrended time series of stream function at $925 \mathrm{hPa}$ over the region $25^{\circ}-40^{\circ} \mathrm{N}, 50^{\circ}-30^{\circ} \mathrm{W}$ (Fig. 3). Figure 3 shows the interannual variation of the NASH intensity index. The composite stream function based on the NASH index greater than 1 and less than -1 demonstrates significant differences in the NASH intensity, proving that the index could well depict the intensity of the NASH (Fig. 4).

Figure 4 shows the regressed MBL cloud anomalies and horizontal wind anomalies at $925 \mathrm{hPa}$ against the NASH intensity index. It is obvious that variation of the NASH intensity is closely related with the variability of MBL clouds in the southeastern flank of the NASH. When the NASH is abnormally stronger, more MBL clouds are formed accompanied with significant northeasterly anomalies in the southeastern flank of the NASH (Fig. 4a).

We conduct a linear regression analysis based on the MBL cloud index defined as the standardized detrended

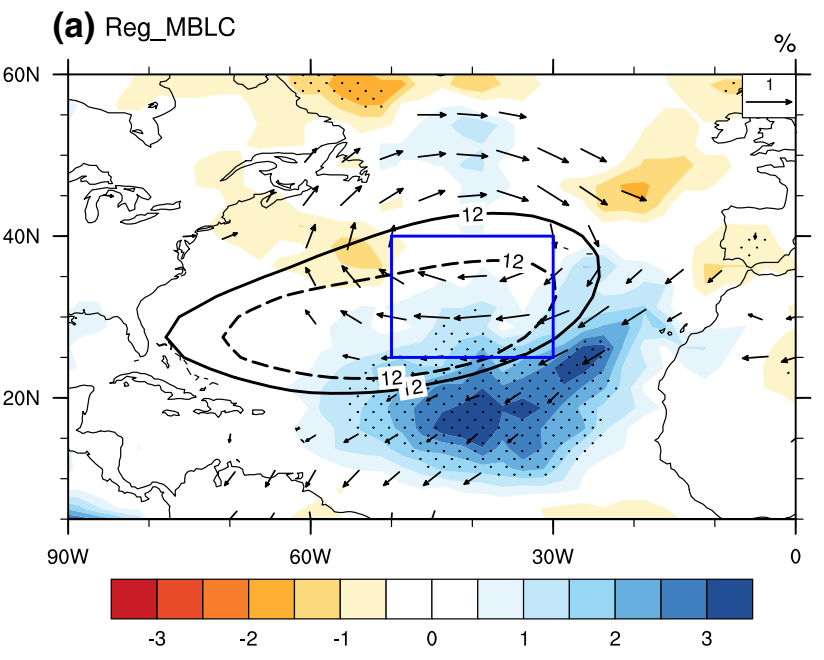

(b) Reg_SF925

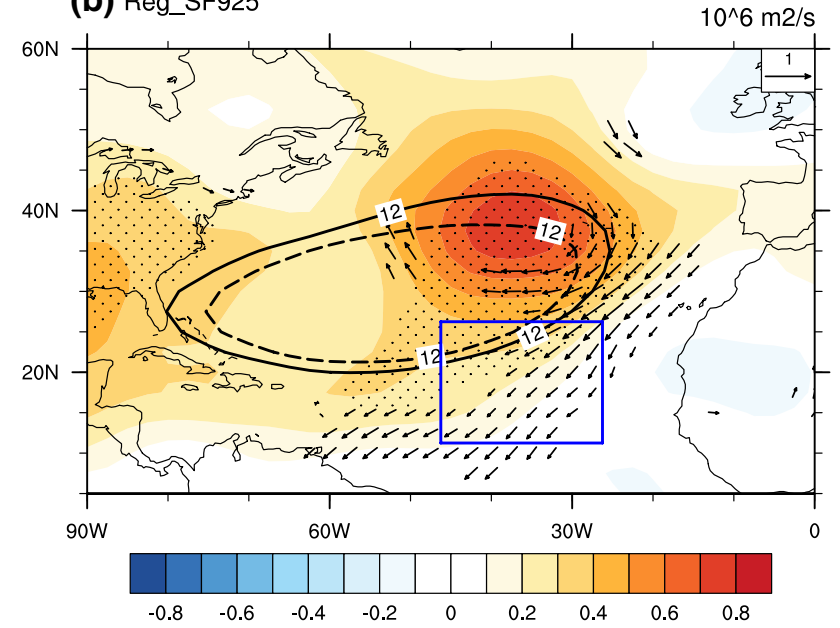

Fig. 4 a Regressed ISCCP MBL cloud (shaded; dots indicate significance level exceeding 0.05 ; unit \%) and horizontal winds at $925 \mathrm{hPa}$ (vector; unit: $\mathrm{m} \mathrm{s}^{-1}$ ) against the NASH intensity, which is defined as the stream function at $925 \mathrm{hPa}$ over the region $25^{\circ}-40^{\circ} \mathrm{N}, 50^{\circ}-30^{\circ} \mathrm{W}$ indicated by blue box. Thick contours indicate composite stream function (isoline $12 \times 10^{6} \mathrm{~m}^{2} \mathrm{~s}^{-1}$ ) at $925 \mathrm{hPa}$ for the NASH index higher than 1 (solid line) and lower than -1 (dashed line). b Regressed stream function (shaded; dots indicate significance level exceeding 0.05 ; unit: $10^{6} \mathrm{~m}^{2} \mathrm{~s}^{-1}$ ) and horizontal winds at $925 \mathrm{hPa}$ (vectors; unit: $\mathrm{m} \mathrm{s}^{-1}$ ) against the MBL cloud index, which is defined as the ISCCP low cloud amount over the region $11.25^{\circ}-26.25^{\circ} \mathrm{N}, 46.25^{\circ}-26.25^{\circ} \mathrm{W}$ indicated by blue box. Thick contours indicate the composite stream function (isoline $12 \times 10^{6} \mathrm{~m}^{2} \mathrm{~s}^{-1}$ ) at $925 \mathrm{hPa}$ for the cloud index higher than 1 (solid line) and lower than -1 (dashed line). Color bar in a represents low cloud amount anomalies in unit \%, and in $\mathbf{b}$ represents stream function anomalies at $925 \mathrm{hPa}$ in unit $10^{6} \mathrm{~m}^{2} \mathrm{~s}^{-1}$

time series of low-level cloud amount over the southeastern North Atlantic $\left(11.25^{\circ}-26.25^{\circ} \mathrm{N}, 46.25^{\circ}-26.25^{\circ} \mathrm{W}\right)$ (Fig. 3) to examine the boundary layer circulation anomalies associated with MBL cloud variability over the subtropical North Atlantic. Figure $4 \mathrm{~b}$ shows the regressed horizontal wind anomalies at $925 \mathrm{hPa}$ against the MBL cloud 
index. Obviously, increased MBL clouds are accompanied by significant northeasterly anomalies and an anomalous anticyclone to the north, implying a stronger NASH. The composite NASH intensity based on the MBL cloud index further verifies that when the MBL clouds are abnormally higher (lower) ${ }^{2}$ than normal, the NASH tends to be strengthened (weakened).

Moreover, the interannual variations of the NASH index and MBL cloud index are highly correlated to each other (Fig. 3). The correlation coefficient between the two indexes is 0.59 , exceeding the 0.01 significance level. This high correlation further indicates that the NASH intensity and the MBL cloud amount are highly coupled with each other. In the next subsection, we focus on the coupling processes between the NASH and MBL clouds over the North Atlantic and examine the underlying physical mechanisms.

\subsection{Physical mechanisms}

\subsubsection{Impact of the NASH circulation on MBL clouds}

Previous studies have established relationships between the lower tropospheric stability (LTS) and MBL clouds (Klein and Hartmann 1993; Wood and Bretherton 2006; Yue et al. 2011). The seasonal maximum low clouds usually correspond to the seasonal greatest lower tropospheric stability; and interannual variations of cloud amount are also related to LTS changes (Klein and Hartmann 1993; Wood and Bretherton 2006). When the boundary layer is warmer than the surface, the boundary layer becomes a thermal inversion layer. The inversion in lower troposphere caps the planetary boundary layer and traps moisture within the MBL, which is favorable for the growth of MBL clouds (Wood and Bretherton 2006). Following Klein and Hartmann (1993), the LTS is calculated as the difference in potential temperature $\theta$ between free troposphere $(700 \mathrm{hPa})$ and the surface $(1000 \mathrm{hPa})$ :

$$
L T S=\theta_{700}-\theta_{0}, \theta=T\left(\frac{p_{0}}{p}\right)^{\kappa}
$$

Figure 5 shows the regressed LTS against the NASH intensity. It is notable that positive LTS anomalies appear in the subtropical North Atlantic east of $45^{\circ} \mathrm{W}$, especially the southeastern flank of NASH along the east coast of the North Atlantic. When the NASH intensifies, the LTS also increases in its southeast flank, facilitating the growth of MBL clouds in the region.

\footnotetext{
${ }^{2}$ MBL cloud index greater than 1 is defined as more cloud condition and less than -1 as less cloud condition.
}

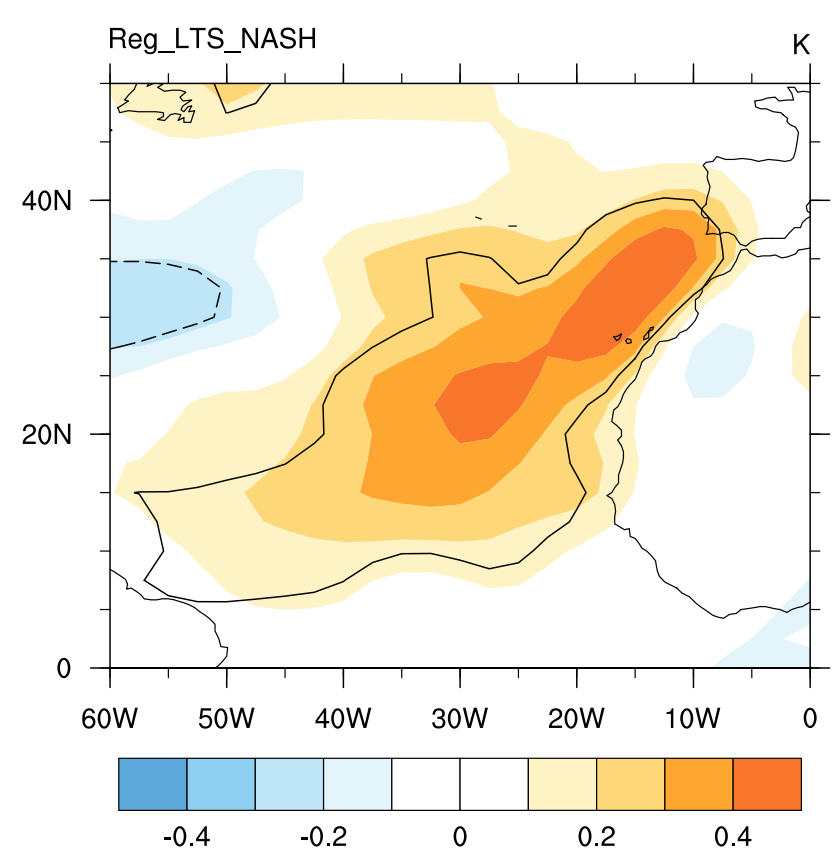

Fig. 5 Regressed LTS against the NASH index (shaded; unit: K). Thick contour indicates significance level exceeding 0.05

Variations of temperature are the key factors in LTS variations. We thus analyze the temperature and horizontal wind anomalies at 700 and $1000 \mathrm{hPa}$, respectively, against the NASH intensity. At $700 \mathrm{hPa}$, warming anomalies are significant over the MBL cloud region, to the south of the anomalous anticyclone associated with intensified NASH (Fig. 6a). The anomalous easterly winds bring warm air from the African continent to the eastern North Atlantic and thus favor the warming over the MBL cloud region. At $1000 \mathrm{hPa}$, significant cooling anomalies appear along the southeast flank of the NASH in association with the strengthened anticyclonic circulation (Fig. 6b). It is the northeasterly winds along the southeastern NASH that lead to the cold advection from the high latitudes to the south, cooling the surface air temperature in the MBL cloud region. As a result, the boundary layer becomes more stable, favoring an increase in the low-level clouds.

The northeasterly anomalies associated with the strengthened NASH not only strengthen the cold advection along the southeast flank of the NASH, but also lead to the offshore ocean current along the western boundary of the African continent (Sverdrup 1947). Figure 7 shows the ocean current anomalies along the east boundary of the North Atlantic $\left(35^{\circ}-15^{\circ} \mathrm{W}\right)$. It indicates that the zonal current anomalies are much stronger than the meridional current anomalies, and the westward currents (i.e., offshore currents) intensify to the north of $20^{\circ} \mathrm{N}$ when the NASH is stronger. These offshore currents induce upwelling and thus lower SSTs in the MBL cloud region (Fig. 8). These 


\section{(a) Reg_T700_uv700}

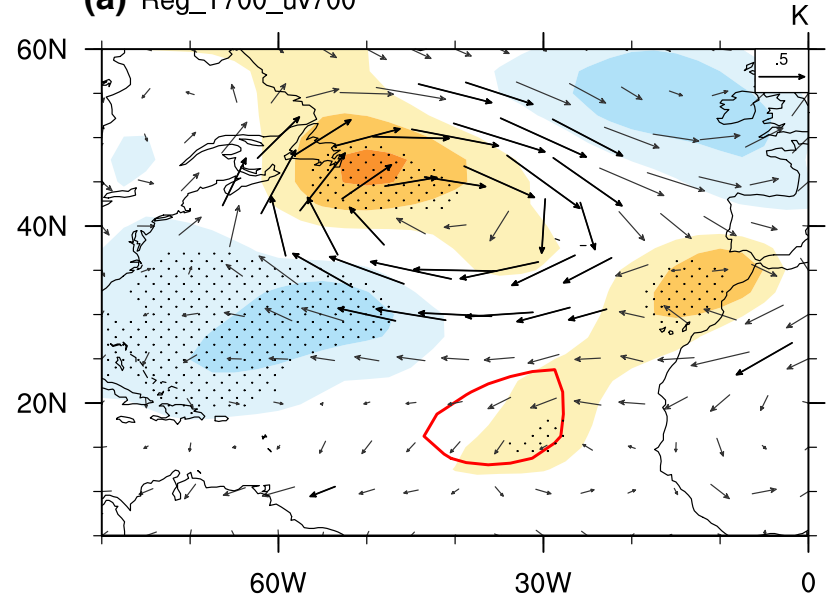

(b) Reg_T1000_uv1000

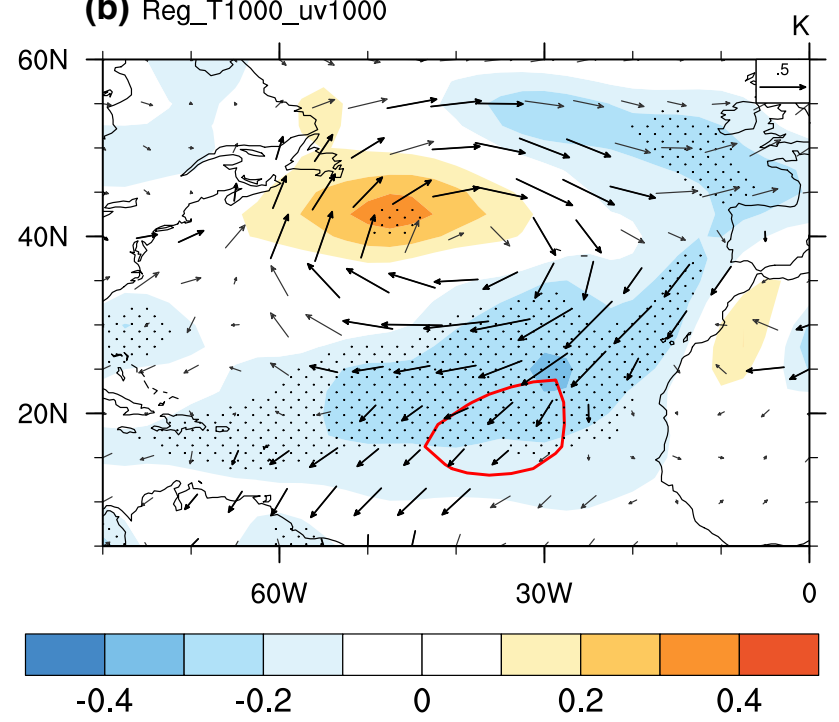

Fig. 6 Regressed air temperature (shaded; unit: K) and horizontal wind anomalies (vectors; unit: $\mathrm{m} \mathrm{s}^{-1}$ ) against the NASH intensity at a $700 \mathrm{hPa}$ and $\mathbf{b} 1000 \mathrm{hPa}$. Temperature and wind anomalies exceeding 0.05 significance level are highlighted by dots and by dark vectors, separately. Red contour indicates climatological MBL cloud amount of $38 \%$

cooling SST anomalies further increase the strength of capping inversion and atmospheric static stability over the MBL cloud region, which favor the formation of more MBL clouds along the southeast flank of the NASH (Fig. 4).

\subsubsection{Feedback of MBL clouds on NASH variability}

MBL clouds have been identified as one of the important factors in the Earth's climate system (Klein and Hartmann 1993). Increased (decreased) MBL clouds lead to less (more) incoming shortwave radiation and stronger (weaker) long-wave radiative cooling. Such heating changes

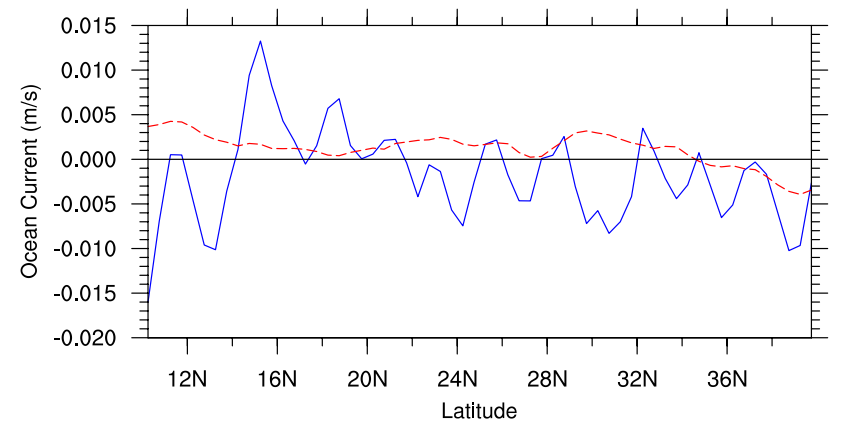

Fig. 7 Latitudinal distributions of SODA zonal ocean current anomalies (blue solid line, unit: $\mathrm{m} \mathrm{s}^{-1}$ ) and meridional ocean current anomalies (red dashed line, unit: $\mathrm{m} \mathrm{s}^{-1}$ ) along $35^{\circ}-15^{\circ} \mathrm{W}$ against the $\mathrm{NASH}$ index

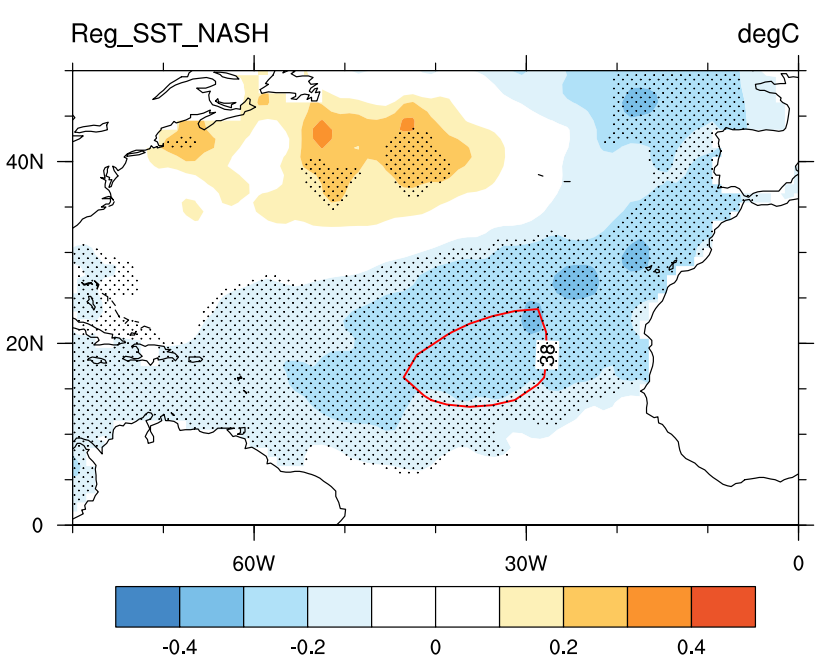

Fig. 8 Regressed SST anomalies from HadISST against the NASH index (shaded; unit: ${ }^{\circ} \mathrm{C}$ ). Areas exceeding the 0.05 significance level are highlighted by dots. Thick contour indicates the climatological MBL cloud amount of $38 \%$

inevitably affect the intensity of subtropical highs (Rodwell and Hoskins 2001; Wu and Liu 2003; Miyasaka and Nakamura 2005; Li et al. 2012b, 2013b). To understand the feedbacks of MBL clouds on NASH intensity and its variability, we carry out additional diagnostic analyses and some numerical experiments.

3.2.2.1 Diagnostic analysis Composite analysis is applied to the vertical profile of apparent heat source $Q_{1}$ over the MBL cloud region $\left(10^{\circ}-25^{\circ} \mathrm{N}, 45^{\circ}-25^{\circ} \mathrm{W}\right)$ based on the MBL cloud index. Figure 9 shows the vertical profile of heating anomalies due to more and less low-level clouds, respectively. When MBL clouds increase, atmospheric air temperatures tend to be lower than normal from the boundary layer to $200 \mathrm{hPa}$. Specifically, heating anomalies are negative in the troposphere above $925 \mathrm{hPa}$, pre- 


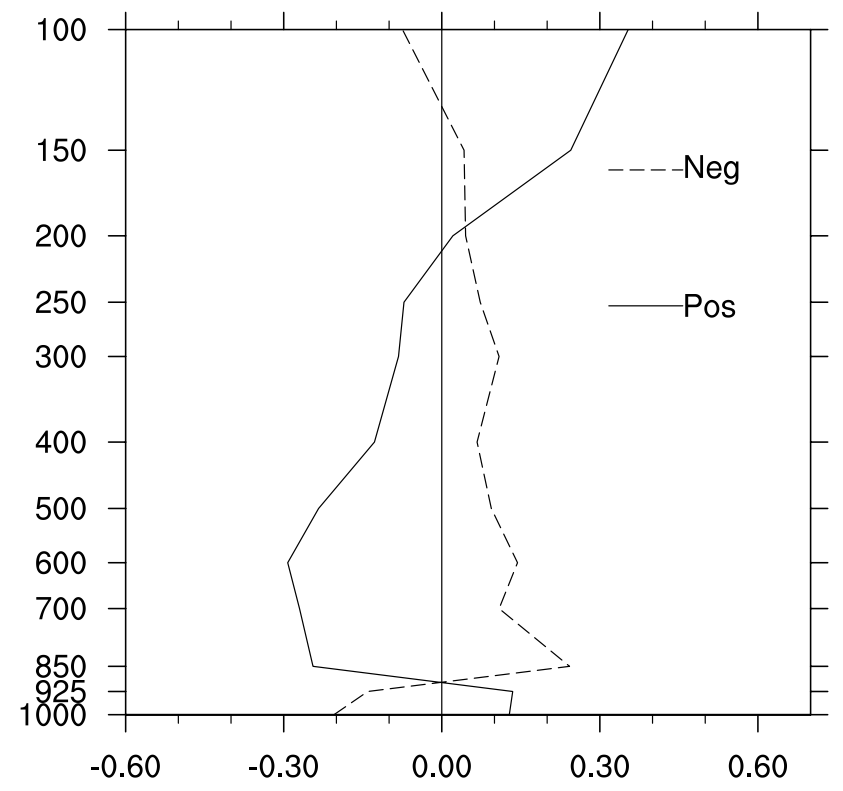

Fig. 9 Vertical profile of $\mathrm{Q}_{1}$ over the $\mathrm{MBL}$ cloud region (unit: $\mathrm{K}$ day $^{-1}$ ). Solid (dashed) line indicates $\mathrm{Q}_{1}$ anomalies in more (less) MBL cloud condition. $\mathrm{Q}_{1}$ is calculated based on NCEP/DOE Reanalysis 2

sumably caused by increased outgoing long-wave radiation and decreased incoming shortwave radiation due to the increase in MBL clouds.

We apply a simplified complete vorticity equation to analyze the effect of MBL clouds on the NASH intensity. Previous studies have demonstrated that the simplified complete vorticity equation could be used to analyze the effect of diabatic heating on the subtropical high on both climatology (Liu et al. 1999, 2001) and interannual variation (Wei et al. 2014, 2015). The equation can be writtern as follows:

$\vec{V} \cdot \nabla \varsigma+\beta v \propto \frac{f+\varsigma}{\theta_{z}} \frac{\partial Q}{\partial z}, \quad \theta_{z} \neq 0$

where $\zeta$ denotes vertical vorticity, $f$ the Coriolis parameter, $\beta$ the Rossby parameter, $v$ meridional wind, $\theta_{z}$ static stability, and $Q$ diabatic heating. Over the subtropical North Atlantic, the meridional velocity $(\beta v)$ is much greater than the vorticity advection term, and the vertical gradient of diabatic heating is negative in the MBL cloud region. According to Eq. (3), this negative gradient must be balanced by significant anomalous northerly wind along the east flank of the NASH (Fig. 5), and the strengthened northerly winds indicate strengthening of the NASH anticyclonic circulation especially at its eastern part.

3.2.2.2 Numerical experiments An anomalous AGCM (Jiang and Li 2005; Li 2006) is utilized to conduct numer- ical experiments to further test the impact of MBL clouds on the NASH intensity. Two idealized numerical experiments are conducted. The negative heating run (NHR) simulates the more MBL cloud condition and the positive heating run (PHR) simulates the less cloud condition. Based on the observed diabatic heating profile at 17 pressure levels (Fig. 9), an idealized 5- $\sigma$ level vertical profile of heating anomalies is estimated to prescribe in the experiments. In the two experiments, the central heating rates at levels $\sigma=0.1,0.3,0.5,0.7$, and 0.9 are $0.05 /-0.05,-0.10 / 0.10,-0.30 / 0.30,-0.25 / 0.25$, and $-0.05 / 0.05 \mathrm{~K} \mathrm{day}^{-1}$, respectively. The experiments are conducted by running the anomalous AGCM for 120 days under a fixed summer (JJA) basic state. The ensemble means of the last 90 days are used to analyze the responses of lower-level atmospheric circulations to the prescribed cooling anomalies associated with the MBL clouds.

Figure 10 illustrates the horizontal wind field at $850 \mathrm{hPa}$ for the PHR and NHR and the difference of the wind anomalies at $850 \mathrm{hPa}$ between NHR and PHR. Similar to observation (Fig. 4b), northeasterly wind anomalies are significant when low-level clouds are abnormally higher over the MBL cloud region. The anomalous cooling center due to the increased MBL clouds excites an anomalous anticyclone. The advection of the negative vorticity associated with cooling by the background easterly contributes to the overall strengthening of NASH (Fig. 10c). Comparing the stream function contours of $11 \times 10^{6} \mathrm{~m}^{2} \mathrm{~s}^{-1}$ between the NHR and PHR simulations (Fig. 10), we find a much larger domain of the anticyclonic circulation in the NHR simulation.

\section{Conclusions and discussions}

This paper has showed the dynamical and thermodynamical interactions between the summertime MBL clouds, NASH circulation, and local SSTs in the subtropical North Atlantic using various cloud data, SSTs, and atmospheric reanalysis data. In boreal summer, abundant MBL clouds are observed over the southeast part of the NASH with a center at about $15^{\circ} \mathrm{N}, 35^{\circ} \mathrm{W}$. The interannual variations of the MBL clouds, the subtropical anticyclonic circulation of NASH, and local SSTs are closely correlated with each other. When the NASH strengthens, northeasterly wind anomalies significantly increase along its southeast flank. Such northeasterly anomalies lead to cold advection in the MBL cloud region, which cools the air temperature at the surface. On the other hand, the northeasterly anomalies may cause anomalous offshore currents along the southeast flank of NASH according to the Sverdrup balance. The offshore currents further lead to oceanic upwelling and lower the SSTs of the subtropical North Atlantic. Meanwhile, 
Fig. 10 Horizontal wind field at $850 \mathrm{hPa}$ (vectors; unit: $\mathrm{m} \mathrm{s}^{-1}$ ) for $\mathbf{a}$ the NHR, $\mathbf{b}$ the PHR and $\mathbf{c}$ their differences (vectors; unit: $\mathrm{m} \mathrm{s}^{-1}$ ). Blue solid (dashed) contour indicates the NASH circulation with stream function $11 \times 10^{6} \mathrm{~m}^{2} \mathrm{~s}^{-1}$ in the NHR (PHR). Red dashed (solid) lines in $\mathbf{a}-\mathbf{c}$ indicate horizontal distribution of the anomalous cooling (heating) center at midlevel $(\sigma=0.5)$ with the heating rate -0.1 and -0.3 (0.1 and 0.3 ) $\mathrm{K} \mathrm{day}^{-1}$ in the NHR (PHR). Only the wind anomalies exceeding 0.001 significance level are shown in $\mathbf{c}$

\section{(a) NHR}

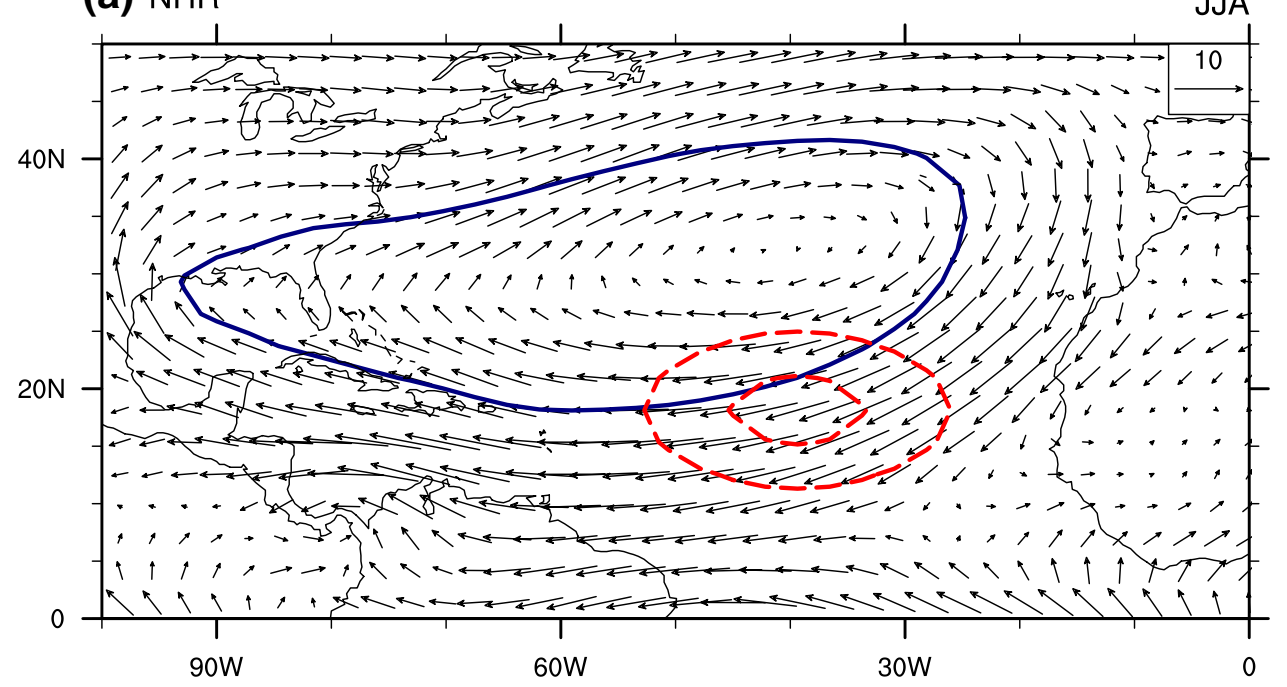

(b) PHR

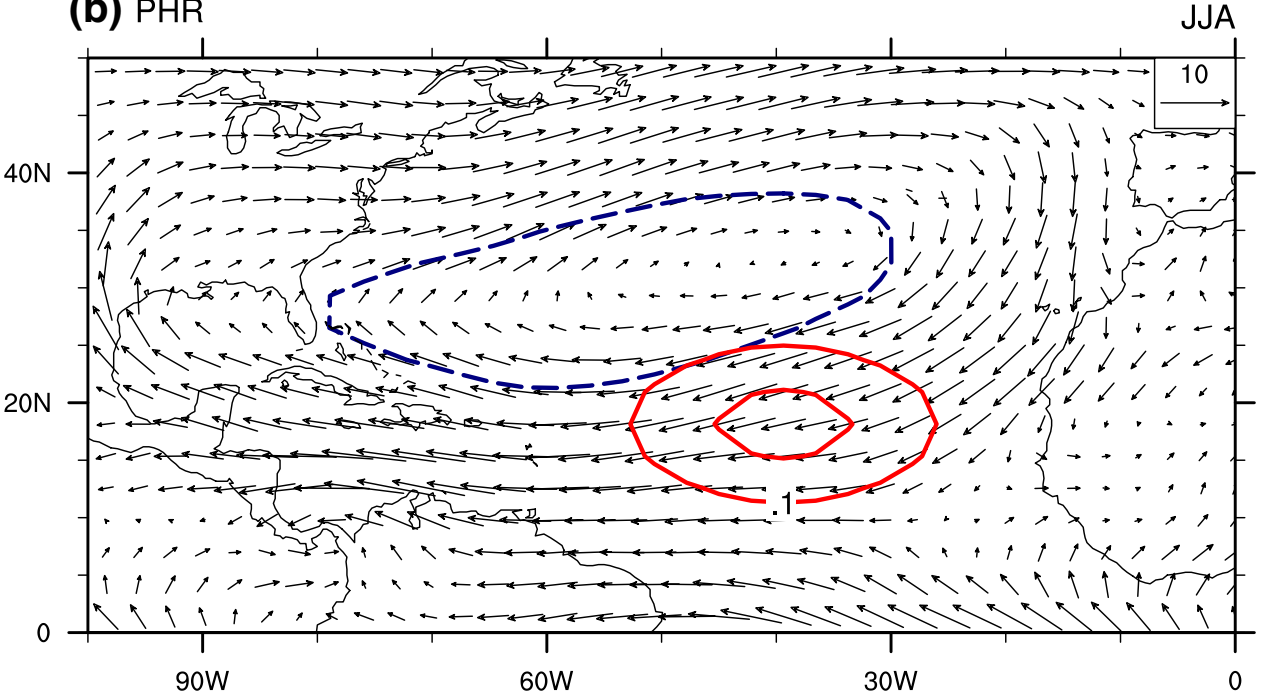

(c) NHR-PHR

JJA 
anomalous easterly winds lead to warm advection from the African continent to the eastern North Atlantic at $700 \mathrm{hPa}$, and result in warm anomalies over the MBL cloud region. The higher air temperature at $700 \mathrm{hPa}$ and the lower temperature at the surface increase the static stability along the southeast flank of the NASH, which favors the growth of MBL clouds in the region.

The intensity of NASH could also be altered due to the variation of MBL clouds. Increased MBL clouds reduce incoming shortwave radiation and enhance long-wave radiative cooling. The changes in diabatic heating associated with MBL clouds tend to increase the northerly winds and enhance the anticyclonic circulation of the NASH. Numerical experiments further confirm the effects of increased (decreased) MBL clouds on the strengthening (weakening) of the NASH: an anomalous anticyclone is excited by the cooling anomaly induced by increased MBL clouds and advection of the negative vorticity associated with the cooling by the background easterly contributes to the strengthening of the NASH.

Climatologically, SST in the North Atlantic MBL cloud region is about $3^{\circ} \mathrm{C}$ warmer than that in the North Pacific cloud region during boreal summer since the NASH is about $5^{\circ}$ closer to the equator. Thus, less MBL clouds (weaker LTS) are typically observed over the North Atlantic. However, on interannual timescale, the coupling between the MBL clouds, underlying SST and subtropical high over the North Atlantic appears to be stronger as illustrated by larger variations of the LTS $(0.28 \mathrm{~K}$ at the North Atlantic vs $0.17 \mathrm{~K}$ at the North Pacific), greater SSTA associated with the subtropical high intensity $\left(-0.23^{\circ} \mathrm{C}\right.$ at the North Atlantic vs $-0.16^{\circ} \mathrm{C}$ at the North Pacific) and a higher correlation coefficient between the subtropical highpressure and the clouds ( 0.59 at the North Atlantic vs 0.26 at the North Pacific). With increasing atmospheric concentrations of greenhouse gases, climate models consistently project a strengthening of the near-surface summertime subtropical high over the North Atlantic (Li et al. 2012b). This result, combined with findings discussed here, suggests that in the near future, more low-level clouds and increased cooling effect will likely occur along the NASH southeast flank. The coupling between a strengthened NASH and more MBL clouds over the subtropical North Atlantic could result in enhanced northeasterly winds, potentially altering steering flows thus tracks of North Atlantic tropical cyclones in the future.

Acknowledgements The authors are very grateful for the constructive comments from two anonymous reviewers, which helped greatly in improving this paper. This study is supported by the NIH Grant NIH-1R21AG044294-01A1. Wei Wei and Song Yang are also supported by the National Key Research Program of China (2014CB953900), the National Natural Science Foundation of China (Grants 41661144019 and 41605040), the "111-Plan" Project of China (Grant B17049), and the Jiangsu Collaborative Innovation Center for Climate Change, China. Yi Deng is supported by the National Science Foundation under Grants AGS-1147601 and AGS1354402. The authors are also grateful of Prof. Tim Li at the University of Hawaii who provided the idealized AGCM.

\section{References}

Bellomo K, Clement AC, Murphy LN, Polvani LM, Cane MA (2016) New observational evidence for a positive cloud feedback that amplifies the Atlantic Multidecadal Oscillation. Geophys Res Lett 43:9852-9859

Bony S, Dufresne JL (2005) Marine boundary layer clouds at the heart of tropical cloud feedback uncertainties in climate models. Geophys Res Lett 32:L20806. doi:10.1029/2005GL023851

Carton JA, Giese BS (2008) A reanalysis of ocean climate using Simple Ocean Data Assimilation (SODA). Mon Weather Rev 136:2999-3017

Carton JA, Chepurin GA, Chen L (2016) An updated reanalysis of ocean climate using the Simple Ocean Data Assimilation version 3 (SODA3). http://www.atmos.umd.edu/ ocean/index_files/ soda3_readme.html

Chepfer H, Bony S, Winker D, Cesana G, Dufresne J, Minnis P, Stubenrauch C, Zeng S (2010) The GCM-oriented CALIPSO cloud Product (CALIPSO-GOCCP). J Geophys Res 115:D00H16. doi:10.1029/2009JD012251

Clement AC, Burgman R, Norris JR (2009) Observational and model evidence for positive low-level cloud feedback. Science 325:460-464

Colbert AJ, Soden BJ (2012) Climatological variations in North Atlantic tropical cyclone tracks. J Clim 25:657-673

Cook KH, Vizy EK, Launer ZS, Patricola CM (2008) Springtime intensification of the Great Plains low-level jet and midwest precipitation in GCM simulations of the twenty-first century. J Clim 21:6321-6340

Davis RE, Hayden BP, Gay DA, Phillips WL, Jones GV (1997) The North Atlantic subtropical anticyclone. J Clim 10:728-744

Dong X, Xi B, Kennedy A, Minnis P, Wood R (2014a) A 19-month record of marine aerosol-cloud-radiation properties derived from DOE arm mobile facility deployment at the azores. Part I: cloud fraction and single-layered MBL cloud properties. J Clim 27:3665-3682

Dong X, Xi B, Wu P (2014b) Investigation of the diurnal variation of marine boundary layer cloud microphysical properties at the Azores. J Clim 27:8827-8835

Dong X, Schwantes AC, Xi B, Wu P (2015) Investigation of the marine boundary layer cloud and $\mathrm{CCN}$ properties under coupled and decoupled conditions over the Azores. J Geophys Res Atmos 120:6179-6191

Elsner J, Tsonis A (1993) Complexity and predictability of hourly precipitation. J Atmos Sci 50:400-405

Freeman E, Woodruff SD, Worley SJ, Lubker SJ, Kent EC, Angel WE, Berry DI, Brohan P, Eastman R, Gates L (2016) ICOADS Release 3.0: a major update to the historical marine climate record. Int J Climatol. doi:10.1002/joc. 4775

He Y (2009) Surface wind speed probability distribution in the Southeast Pacific of Marine Stratus and Stratocumulus regions. Cent Eur J Geosci 1:443-455

Held IM, Suarez MJ (1994) A proposal for the intercomparison of the dynamical cores of atmospheric general circulation models. Bull Am Meteor Soc 75:579-593

Huang L, Jiang JH, Wang Z, Su H, Deng M, Massie S (2015) Climatology of cloud water content associated with different 
cloud types observed by A-Train satellites. J Geophys Res Atmos 120:4196-4212

Jiang X-A, Li T (2005) Reinitiation of the boreal summer intraseasonal oscillation in the tropical Indian Ocean. J Clim 18:3777-3795

Kanamitsu M, Ebisuzaki W, Woollen J, Shi-Keng Y (2002) NCEP-DOE AMIP-II reanalysis (R-2). Bull Am Meteor Soc 83:1631-1643

Klein SA, Hartmann DL (1993) The seasonal cycle of low stratiform clouds. J Clim 6:1587-1606

Li T (2006) Origin of the summertime synoptic-scale wave train in the western North Pacific. J Atmos Sci 63:1093-1102

Li W, Li L, Fu R, Deng Y, Wang H (2011) Changes to the North Atlantic subtropical high and its role in the intensification of summer rainfall variability in the Southeastern United States. J Clim 24:1499-1506

Li L, Li W, Kushnir Y (2012a) Variation of the North Atlantic subtropical high western ridge and its implication to Southeastern US summer precipitation. Clim Dyn 39:1401-1412

Li W, Li L, Ting M, Liu Y (2012b) Intensification of Northern Hemisphere subtropical highs in a warming climate. Nat Geosci 5:830-834

Li L, Li W, Barros AP (2013a) Atmospheric moisture budget and its regulation of the summer precipitation variability over the Southeastern United States. Clim Dyn 41:613-631

Li W, Li L, Ting M, Deng Y, Kushnir Y, Liu Y, Lu Y, Wang C, Zhang P (2013b) Intensification of the Southern Hemisphere summertime subtropical anticyclones in a warming climate. Geophys Res Lett 40:5959-5964

Liu YM, Wu GX (2004) Progress in the study on the formation of the summertime subtropical anticyclone. Adv Atmos Sci 21: 322-342

Liu YM, Wu GX, Liu H, Liu P (1999) The effect of spatially nonuniform heating on the formation and variation of subtropical high part III: condensation heating and South Asia high and western Pacific subtropical high. Acta Meteorol Sin 57:525538 (in Chinese)

Liu YM, Wu GX, Liu H, Liu P (2001) Condensation heating of the Asian summer monsoon and the subtropical anticyclone in Eastern Hemisphere. Clim Dyn 17:327-338

Liu YM, Wu GX, Ren RC (2004) Relationship between the subtropical anticyclone and diabatic heating. J Clim 17:682-698

Luo H, Yanai M (1984) The large-scale circulation and heat sources over the Tibetan Plateau and surrounding areas during the early summer of 1979. Part II: Heat and moisture budgets. Mon Weather Rev 112:966-989

Miller RL (1997) Tropical thermostats and low cloud cover. J Clim 10:409-440

Minnis P, Young DF, Sunmack S, Heck PW, Doelling DR, Trepte QZ (2004) CERES cloud property retrievals from imagers on TRMM, Terra, and Aqua. In: Proceedings of SPIE: The International Society for Optical Engineering 5235:37-48

Miyasaka T, Nakamura H (2005) Structure and formation mechanisms of the Northern Hemisphere summertime subtropical highs. J Clim 18:5046-5065

Nigam S, Chan SC (2009) On the summertime strengthening of the Northern Hemisphere Pacific sea level pressure anticyclone. J Clim 22:1174-1192

Norris JR (1998) Low cloud type over the ocean from surface observations. Part II: Geographical and seasonal variations. J Clim 11:383-403

Norris JR (2000) Interannual and interdecadal variability in the storm track, cloudiness, and sea surface temperature over the summertime North Pacific. J Clim 13(2):422-430
Norris JR, Klein SA (2000) Low cloud type over the ocean from surface observations. Part III: Relationship to vertical motion and the regional surface synoptic environment. J Clim 13:245-256

Norris JR, Leovy CB (1994) Interannual variability in stratiform cloudiness and sea surface temperature. J Clim 7:1915-1925

Norris JR, Zhang Y, Wallace JM (1998) Role of low clouds in summertime atmosphere-ocean interactions over the North Pacific. J Clim 11:2482-2490

Randall DA et al (2007) Climate models and their evaluation. In: Solomon $\mathrm{S}$ et al (eds) Climate change 2007: the physical science basis. Cambridge University Press, Cambridge, pp 589-662

Rayner N, Parker DE, Horton E, Folland C, Alexander L, Rowell D, Kent E, Kaplan A (2003) Global analyses of sea surface temperature, sea ice, and night marine air temperature since the late nineteenth century. J Geophys Res Atmos. doi:10.1029/2002JD002670

Rodwell MJ, Hoskins BJ (2001) Subtropical anticyclones and summer monsoons. J Clim 14:3192-3211

Rossow WB, Schiffer RA (1991) ISCCP cloud data products. Bull Am Meteor Soc 72:2-20

Rossow WB, Schiffer RA (1999) Advances in understanding clouds from ISCCP. Bull Am Meteor Soc 80:2261-2287

Sassen K, Wang Z (2008) Classifying clouds around the globe with the CloudSat radar: 1-year of results. Geophys Res Lett 35:L04805. doi:10.1029/2007GL032591

Schubert WH, Wakefield JS, Steiner EJ, Cox SK (1979) Marine stratocumulus convection. Part I: Governing equations and horizontally homogeneous solutions. J Atmos Sci 36:1286-1307

Seager R, Murtugudde R, Naik N, Clement A, Gordon N, Miller J (2003) Air-sea interaction and the seasonal cycle of the subtropical anticyclones. J Clim 16:1948-1966

Stahle DW, Cleaveland MK (1992) Reconstruction and analysis of spring rainfall over the southeastern US for the past 1000 years. Bull Am Meteor Soc 73:1947-1961

Sverdrup HU (1947) Wind-driven currents in a baroclinic ocean; with application to the equatorial currents of the eastern Pacific. Proc Natl Acad Sci 33:318-326

Wang L, Li T, Zhou T (2012) Intraseasonal SST variability and airsea interaction over the Kuroshio Extension region during boreal summer. J Clim 25:1619-1634

Wei W, Zhang R, Wen M, Rong X, Li T (2014) Impact of Indian summer monsoon on the South Asian high and its influence on summer rainfall over China. Clim Dyn 43:1257-1269

Wei W, Zhang R, Wen M, Kim B-J, Nam J-C (2015) Interannual variation of the South Asian high and its relation with Indian and East Asian summer monsoon rainfall. J Clim 28:2623-2634

Wei W, Zhang R, Wen M, Yang S (2017) Relationship between the Asian westerly jet stream and summer rainfall over central Asia and North China: roles of the Indian monsoon and the South Asian high. J Clim 30:537-552. doi:10.1175/JCLI-D-15-0814.1

Wielicki BA, Barkstrom BR, Baum BA, Charlock TP, Green RN, Kratz DP, Lee RB, Iii, Minnis P, Smith GL, Wong T (1996) Clouds and the Earth's Radiant Energy System (CERES): algorithm overview. Bull Am Meteor Soc 36:1127-1141

Wood R (2012) Review: stratocumulus clouds. Mon Weather Rev 140:2373-2423

Wood R, Bretherton CS (2006) On the relationship between stratiform low cloud cover and lower-tropospheric stability. J Clim 19:6425-6432

Wu G, Liu Y (2003) Summertime quadruplet heating pattern in the subtropics and the associated atmospheric circulation. Geophys Res Lett 30:1201. doi:10.1029/2002GL016209

Wu G, Liu Y, Zhu X, Li W, Ren R, Duan A, Liang X (2009) Multiscale forcing and the formation of subtropical desert and monsoon. Ann Geophys Atmos Hydrosph Space Sci 27:3631-3644 
Yanai M, Esbensen S, Chu J-H (1973) Determination of bulk properties of tropical cloud clusters from large-scale heat and moisture budgets. J Atmos Sci 30:611-627

Yue Q, Kahn BH, Fetzer EJ, Teixeira J (2011) Relationship between marine boundary layer clouds and lower tropospheric stability observed by AIRS, CloudSat, and CALIOP. J Geophys Res 116:D18212. doi:10.1029/2011JD016136

Zhai C, Jiang JH, Su H (2015) Long-term cloud change imprinted in seasonal cloud variation: more evidence of high climate sensitivity. Geophys Res Lett 42:8729-8737
Zhang X, Walsh JE, Zhang J, Bhatt US, Ikeda M (2004) Climatology and interannual variability of Arctic cyclone activity: 19482002. J Clim 17:2300-2317

Zhang GJ, Vogelmann AM, Jensen MP, Collins WD, Luke EP (2010) Relating satellite-observed cloud properties from MODIS to meteorological conditions for marine boundary layer clouds. J Clim 23:1374-1391 